\title{
Last Kilometer Distribution Pattern Analysis of Electricity Supplier Logistics in Chinese Mainland
}

\author{
Peng Qian ${ }^{1}$ \\ ${ }^{1}$ Anhui Sanlian University, Hefei 230601, China
}

Keywords: Distribution pattern, electricity supplier logistics, Chinese mainland, the last kilometer

\begin{abstract}
In recent years, some of these electric logistics companies andresearchersof related organizations at home and abroad, have been doinga lot of workonproblems the Last Kilometer distributionof electricity supplier logistics exists, and have obtained corresponding study achievements. Among them, the application inGermany intelligent package transceiver station system of DHL air Cargo Company is a typical example, andit has changed from the previous unitary distribution model to diversified and intelligent distribution model. Although this model is very good, the environment has put forward certain requirements. In China, itcannot be directly applied, but we can learn useful experience in our favor and make the actual situation of China's mainland customer groups as the base, and establish intelligent self-lifting containers,service collection points and delivery model to meet current electricity supplier development needs of the times.
\end{abstract}

\section{Last Kilometer delivery environment of electricity supplier logistics in Chinese mainland}

E-commerce is information technology and networking product in the 20th century, and a new business model. In the information age, the applicationof Internet and big data is in a rising trend, and the popularity of the Internet. On this basis, E-commerce has obtained a wide range of applications and development, as long as the Internet can be achieved,the online trading activities can be taken, and the online trading is not lot worse than traditional trading. China developed new rural construction to achieve the villagesproject, corresponding facilities have also been further improved, particularly in the overlay network, and the new generation of farmers learned the online trading of agricultural products and online shopping, although the volume is lower than in urban areas, its customers and volume is increasing every year. Followed by the Last Kilometer distribution tasks which can be imagined.

Chinese population is concentrated mainly in cities, most of which have relatively simple life way, namely,the distance between the workplace and home is also themain Last Kilometer distribution rangeof electricity supplier logistics. Although the distributionlocation is relatively simple,customeroften cannot receive normal receiptin practice. The main reason is: in normal working schedule, the community mostly elderly or children; and for some high-end communities, there is more stringent management, andouter workers are difficult to enter the community. Secondly, the unit is usually not allowed to send and receive personal belongings during working hours. Last Kilometerdelivery staff of electricity supplier logisticscannotconsult with customers, guard or janitor room,for the staff of guard or the janitor's room, placing the customer items here intangibly increases workload but also bear some risks. If there is cargo loss, stole, error-took and some other phenomena, it is bound to cause resentment of relevant personnel.

Compared with the urban population, rural population is naturally not so concentrated, and the livingway is different, basically exclusive single-family. Some villages have only a few families or even only one family in the hills or in remote areas. For today'selectronic commerce age, 
althoughonline trading in rural areas has a clear upward trend, the logistics business is a severe test. If the Last Kilometerdelivery issues are not well, it will also increase their costs. For example, customers in rural buys a commodityof a few yuan online, thelast kilometer delivery personnel of electricity supplier logistics has to drive a few kilometers or even longer journey, which is a bit unrealistic. Thus, forthe distribution rangeof rural electricity supplier logistics last kilometer, with the exception of China Post's EMS, the farthest place of other logistics companies can only delivere to the township streets, then by the customer from mentioning. The China Post has no dead dot structure, which cannot be ignored for any private express delivery companies, and they should learn from each other to make their own service characteristics and better service delivery.

Online shopping is a more stylish and convenient way to shop. When customers buy goods on the Internet, they will prefer the same kinds of commodities withequalprice and free shipping business. If you do not support this service, customers will want to be able to pay cash on delivery terms in order to reduce the risk of shopping. However, this service approach is in the minority, mostly paying the freight in advance. Another service is the free shipping service mentioned earlier, in fact, the so-called free shipping freight business has included it in the commodity prices which are part of the cost of goods. But to the customer psychology, itbrings benefits.

At this stage, China is still a developing country, although people's living conditions continue to improve, compared to some developed countries in Europe and America, there is still a gap. Among them, private car ownership is rising year by year, road traffic congestion has still not been solved. Therefore, customers want electricity supplier logistics to provide door to door service, or service that sets up collection points in the community. In summary, the characteristics of the last kilometer delivery environmentof e-commerce in China mainland at this stage include: First, the huge customer groups, the urbanrelatively concentrated and rural scattered, involving a wide range; second,time differences inreceiving goods, picking inconveniently; third, the transportation is not convenient, desirable to provide door-to-door service.

\section{Electricity supplier customer groups division in Chinese mainland}

The popularity of Internet and thewidespread use of smart phones, let to that electric business customer group's category is more and more, but in general, it can be divided into four categories: unit staff, students, rural and other personnel.

The first customer group is unit staff, which mainly refers toservice personnelin enterprises and institutions, government agencies, people's organizations and other so on, whose main characteristics are: First, the working time is generally not permitted to handle private things, such as receiving delivery; Second,customer groups are large, but the workplace is relatively scattered compared with student apartment; Third, the shipping address is clear with the majority of small items.

Thus, such groups have difficulty in sending and receiving the goods, hoping to raise a container or through intelligent janitor to solve the problem. Electricity supplier logistics companies can providecorresponding service measures for different situations, such as building intelligent mention containers in units or communitiessending and receiving large number of cargos; on the contrary, a small number of customerneedscan be done by reception or janitor room, to meet customer needs as soon as possible.

The second category of customer groups is students, which usually refers to students enrolled in colleges and universities, whose characteristics are four: First, the residentialform is apartmentwhich is focus; secondly, theclass time of each classis not uniform, but the timeduring the break is more and uniform; again, the major groups buy shopping network products with small size 
and low price; finally, send and receive goods outside concentrate, and non-school personnel is prohibited from wandering in and out of campus.

Therefore, for the student population, it is unable to provide door-to-door service, and the more effective method is to create self-service lockers in every apartment. In addition, the popularity of smart phones leads to thatthe students can simply sweep the two-dimensional code on the self-service lockersto achieve sending and receiving flow of goods, which not only facilitates the student customer groups, but also improves the efficiency of logistics and distribution, also avoids items loss, error taking and some other phenomena.

The third group of customers is rural people, which mainly refers to that the transceiver of the goods is in the rural areas, and the characteristics of these customer groups are: first, the network coverage in rural areas are gradually comprehensive, and online transactions increase year by year, but still below the city; second, shipping address is relatively dispersed with high distribution costs; third, people are in the field work at the busy season, with no one at home to receive the goods.

Thus, we can build fixed point of servicein the rural township streets, but alsoestablish cooperative relations with the postal towns or large supermarkets, shops, also can set up self-help lift container to facilitate the rural people to send and receive goods.

The fourth category of customers is other personnel, which mainly refers to the home office staff, full-time wife, and the elderly and so on. The main features of such customer groups are: First, online transactions of goods are various withlarge sizes; Second, there is plenty of time, you can achieve door-to-door service; Third, there is more casual time of receipt, with delivery to the door.

Thus, we can see that it is difficult for the electricity supplier customer groups to adopt last unifiedkilometer distributionmodel. The best distribution program is using different distribution model with respect to different customer groups, to maximally meetthe different needs of the same or different types of customer groups.

\section{Last Kilometer integrated distribution pattern of customer-centric electricity supplier logistics}

Drawn from theanalysis of customer groups division and characteristic, the last kilometer distributionproblemin China mainland electricity supplier logistics is: the distribution costs and time differences and goods from convenience, combined with Chinamainland e-commerce customers, we conduct a comprehensive analysis of the specific circumstances of groups, as well as the last kilometer delivery environment and development of the electricity supplier logistics. Studies suggest that: the establishment of intelligent self-extract container and artificial diversity indirect distribution model and the integrated distribution modelcombined artificial receiving and direct home delivery can meet the needs of the domestic status quo of the current e-commerce, and achieve the customer-centric electricity supplier logistics last kilometer integrated distribution model. Most of its distribution terminal is divided into three modes: First, artificial delivery point; Second, the automatic lifting containers; Third, delivery.

In the aforementioned section, customer groups are mainly divided into staffofunits, students, rural and other personnel. These customer groupshave different needsfor electricity supplier logistics last kilometer delivery mode, even the same kind of customer groups often have different service needs. Thus, the integrated distribution model of customer-centric electronic business logistics last kilometer basically summarizes the various groups of different individual needs, with a flexible and effective way to solve the distribution problemsbetween customer applications and the last kilometer to achieve best mutual benefit.

For the establishment of intelligent self-extract container and artificial diversity indirect 
distribution model, the core problem is the location.On this issue, we should fully consider the convenience of the customer receiving the goods, to the extent possible to take care of all the customers nearby. For example, communities usually have more than two outdoors, you can create a variety of indirect distribution model in the vicinity of each gate, with the principle of the nearest for convenience of customers. Therefore, combined distribution pattern of intelligent self-extract container and artificial containers has meaning.

The core content of last kilometer integrated distribution model of customer-centric electronic business logistics is for the convenience of customers, to meet the distribution needs of different customers, and improve service quality. And on this basis, with the maximum optimization of last kilometer logistics resourcesconfiguration, it will reduce distribution costs, avoid the loss, wrong or take delivery failure of the cargo that occurred during distribution. Achieve the lowest costof logistics companies can make customers enjoy the highest quality of service, which adapts to the rapid development of the electricity supplier logistics.

\section{References}

[1] Lin F. Analysis of China's Distribution Model. Southwest Jiaotong University, 2004. (In Chinese)

[2] Liu D. Research on Problem Solution of Business Enterprise Last Kilometer.Management Observation, 2013 (14): 45.(In Chinese)

[3] Wang J.Expand Research on Delivery Last Kilometer Problem. Logistics Engineering and Management, 2015 (2): 1-2. (In Chinese)

[4] Yang J, Yang C, Yao X. Research onLast Kilometer Problems of Electricity Supplier Logistics. Business Economics and Management, 2014, 4: 35-37. (In Chinese) 